\title{
PROGNOSIS IN ADVANCED NON-SMALL CELL LUNG CANCER - A RETROSPECTIVE STUDY EXAMINING ECOG PERFORMANCE STATUS SCORES OF PATIENTS
}

\author{
NIDA SAJID ALI BANGASH ${ }^{1}$, NATASHA HASHIM ${ }^{2}$, NAHLAH ELKUDSSIAH ISMAIL ${ }^{3 *}$
}

${ }^{1}$ Department of Pharmacy, Clinical BioPharmaceutics Research Group, Universiti Teknologi MARA, Puncak Alam Campus, 42300 Bandar Puncak Alam, Selangor, Malaysia. ${ }^{2}$ Department of Oncology and Radiotherapy, Hospital Kuala Lumpur, 50300 Kuala Lumpur, Malaysia. ${ }^{3}$ Dean's office, Faculty of Pharmacy, MAHSA University, Jalan SP2, Bandar Saujana Putra, 42610 Jenjarom Kuala Langat, Selangor. Email: elkudssiah77@yahoo.com

Received: 17 January 2017, Revised and Accepted: 02 February 2017

\section{ABSTRACT}

Objective: Increasing prevalence and poor survival of advanced incurable non-small cell lung cancer (NSCLC) make it a major health problem globally, especially in developing countries. This awakens need for identification of the strongest prognostic factor that helps in the selection of appropriate treatment and hence palliates symptoms and improves survival. Lung cancer treatment guidelines advise performance status (PS) as the most established prognostic factor in advanced NSCLC patients. This study investigated the prognostic significance of PS.

Methods: An observational study was done for 163 advanced NSCLC adult Malaysian patients in Radiotherapy and Oncology Clinic, Hospital Kuala Lumpur, Malaysia. Demographic and clinical data were recorded. Kaplan-Meier test was used to measure median overall survival (OS) and Cox proportional hazard model to calculate the hazard ratio for different categories of Eastern Cooperative Oncology Group (ECOG) PS.

Results: The mean age and body weight were $56.7 \pm 10.1$ years old and $57.42 \pm 13.5 \mathrm{~kg}$, respectively. Majority patients were male (68.7\%), Stage IV NSCLC (65.0\%), and ECOG PS score of 2 (41.1\%). ECOG PS had a significant association with age and body weight. Median OS was least for ECOG PS score of 4 (253 days) and was statistically significant ( $\mathrm{p}=0.003)$. ECOG PS was a significant independent prognostic factor for survival in advanced NSCLC patients $(\mathrm{p}<0.001)$.

Conclusion: PS is a strong prognostic factor in advanced NSCLC.

Keywords: Performance status, Survival, Advanced non-small cell lung cancer.

(C) 2017 The Authors. Published by Innovare Academic Sciences Pvt Ltd. This is an open access article under the CC BY license (http://creativecommons. org/licenses/by/4. 0/) DOI: http://dx.doi.org/10.22159/ajpcr.2017.v10i9.17134

\section{INTRODUCTION}

Non-small cell lung cancer (NSCLC) is one of the growing public health problems in Malaysia. At diagnosis, most patients presented with inoperable advanced disease [1]. Locally advanced or metastatic disease treatment is palliative not curative. In advanced NSCLC, prognosis is the fundamental factor that influences the treatment decisions. Better prognostic tools are needed to avoid the use of unnecessary, harmful therapy in the end-stage life. Lung cancer treatment guidelines advised performance status (PS) as the most established factor for assessing prognosis [2].

PS is the assessment of patient's fitness. It measures the impact of tumour symptoms, together with other pre-existing medical problems with a patient's daily life and ability of self-care [3]. In oncologic practice, PS is widely used as it correlates with survival duration of patients [4]. Two most commonly employed scales are the Karnofsky scale [5] created at the beginning of chemotherapy era and the Eastern Cooperative Oncology Group scale (ECOG) of PS. ECOG PS is an evaluation scale of $0-5$ based on the level of symptoms affecting normal activity and the proportion of waking hours spent in bed [6]. ECOG PS scores are described in Fig. 1. PS is a strong independent prognostic factor of survival in advanced NSCLC $[7,8]$.

Numerous studies are available on the prognostic significance of PS in advanced NSCLC patients mainly from developed countries. However, to date, no such data are published in Kuala Lumpur, Malaysia. Therefore, the present study aimed to investigate the prognostic significance of PS in advanced NSCLC adult Malaysian patients. Data obtained from this study later may help the clinical oncologists and clinical pharmacists, especially in Kuala Lumpur, Malaysia, to use ECOG PS as a more effective prognostic tool in advanced NSCLC adult Malaysian patients.

\section{METHODS}

A retrospective observational study was conducted at Radiotherapy and Oncology Clinic, Hospital Kuala Lumpur, Malaysia, between 1 September 2014 and 31 January 2015. The study was approved by Postgraduate Academics and Ethics Committee, Faculty of Pharmacy, Universiti Teknologi MARA (UiTM), Research Ethics Committee, Research Management Institute and Medical Research and Ethics Committee, Ministry of Health, Malaysia.

This study included 163 adult Malaysian patients ( $\geq 18$ years old) that had histological confirmed locally advanced (Stage III A) or metastatic (Stage III B, Stage IV) NSCLC and was on chemotherapy treatment. Age, gender, body weight, clinical stage, and ECOG PS score were noted at the time of diagnosis of disease. To calculate survival time, date of diagnosis, date of the last follow-up and date of death were recorded.

Statistical analysis was conducted using SPSS 21.0 version. Demographic and medical data variables were analyzed descriptively. Pearson $\chi^{2}$ tests were used to find the association of demographic and medical data variables with categories of ECOG PS. Multinomial logistic regression was carried out to find the relationship of ECOG PS with patient's demographic and medical data. For survival analysis, survival time was calculated in days and defined as the time from diagnosis of the disease until death or censored if alive or lost follow-up. To evaluate the prognostic significance of PS, Kaplan-Meier method was used to measure median overall survival (OS) time for EGOG PS scores and 
log-rank test for comparison of the survival curve. Cox proportional hazard regression was run to investigate the effect of the ECOG PS scores on death by estimating the hazard ratio. Groups where $n \leq 10$ were not reported. Statistically significant was assumed for a two-tailed $\mathrm{p}<0.01, \mathrm{p}<0.05, \mathrm{p}<0.001$.

\section{RESULTS}

There were 163 patients included in the study. The overall mean age of enrolled patients was $56.7 \pm 10.1$ years old. Most were male, having overall mean body weight $57.42 \pm 13.5 \mathrm{~kg}$ and Stage IV NSCLC (Table 1). ECOG PS showed significant association with age and body weight (Table 2). There was no significant relationship between ECOG PS and other independent study variables. Majority patients had an ECOG PS of 2 (41.1\%) followed by $35.0 \%$ having ECOG PS of 3. Univariate overall survival analysis for EGOG PS scores of advanced NSCLC patients showed that median OS for $\mathrm{PS}=2$ was 377 days, for $\mathrm{PS}=3$ was

Table 1: Patient demographic and medical data

\begin{tabular}{llll}
\hline Variable & Category & $\begin{array}{l}\text { Advanced } \\
\text { NSCLC (n=163) }\end{array}$ & n (\%) \\
\hline Age (Years old) & Mean \pm SD & $56.7 \pm 10.1$ & \\
& Minimum & 22 & \\
Gender & Maximum & 81 & $112(68.7)$ \\
& Male & & $51(31.3)$ \\
Body weight (kg) & Female & & \\
& Mean \pm SD & $57.42 \pm 13.5$ & \\
& Minimum & 30 & $18(11.0)$ \\
NSCLC Stage & Maximum & 114 & $39(23.9)$ \\
& III A & & $106(65.0)$ \\
\hline & III B & & \\
\hline
\end{tabular}

SD: Standard deviation, NSCLC: Non-small cell lung cancer
397 days, and for $\mathrm{PS}=4$ was 253 days (Table 3). The difference in OS was statistically significant ( $\mathrm{p}=0.003$ ), (Fig. 2). Multivariate analysis showed that PS was the predictor of survival in advanced NSCLC patients $(\mathrm{p}<0.001)$ (Table 3)

\section{DISCUSSION}

In the present study, the overall mean age of the study patients at presentation was found to be $56.7 \pm 10.1$ years old. The results obtained in two other published Malaysian studies by Liam et al. [9], and Hashim et al. [10] stated that overall mean age was $60.3 \pm 11.6$ years old. The differences in the mean age of patients in the present study and previously published two studies might be attributed to differences in the inclusion-exclusion criteria of study. The present study only involved unresectable NSCLC patients while both previously published studies included unresectable NSCLC patients along with minor percentages of resectable NSCLC patients.

Male gender formed the predominant group of adults NSCLC patients $(68.7 \%)$. Similar results were obtained in different study locations of Malaysia by Liam et al. [9], and Hashim et al. [10], where the male was more frequently suffering from NSCLC. Youlden et al. [11] stated that despite geographical differences, lung cancer had higher incidence worldwide among males as compared to females.

The current study showed that at diagnosis, most patients were suffering from Stage IV NSCLC. This finding is in agreement with a study carried out in Thailand by Kitiporn et al. [12] where Stage IV was the most common clinical stage of NSCLC. Increased frequency of metastatic NSCLC may be attributed to the late presentation and heterogeneous nature of the disease.

Results of Table 2 depicted that ECOG PS was significantly associated with age and body weight of adult NSCLC patients. Similarly, Kawaguchi et al. [13] in their study on NSCLC patients found a significant association

Table 2: Association of EGOG PS with advanced NSCLC patient demographic and medical data

\begin{tabular}{|c|c|c|c|c|c|c|}
\hline \multirow[t]{2}{*}{ Variable } & \multicolumn{5}{|c|}{ ECOG PS scores (n=163), n (\%) } & \multirow[t]{2}{*}{$\mathbf{p}^{\mathbf{a}}$} \\
\hline & $\mathbf{0}$ & 1 & 2 & 3 & 4 & \\
\hline \multicolumn{7}{|c|}{ Age (Years old) } \\
\hline $18-40$ & $0(0.0)$ & $5(3.0)$ & $4(2.4)$ & $3(1.8)$ & $1(0.6)$ & \multirow{3}{*}{$0.008^{*}$} \\
\hline $41-64$ & $3(1.8)$ & $22(13.4)$ & $40(24.5)$ & $47(28.8)$ & $6(3.6)$ & \\
\hline$\geq 65$ & $0(0.0)$ & $2(1.2)$ & $23(14.1)$ & $7(4.2)$ & $0(0.0)$ & \\
\hline \multicolumn{7}{|l|}{ Gender } \\
\hline Male & $3(1.8)$ & $18(11.0)$ & 45 (27.6) & $40(24.5)$ & $6(3.6)$ & \multirow[t]{2}{*}{0.556} \\
\hline Female & $0(0.0)$ & $11(6.7)$ & $22(13.4)$ & $17(10.4)$ & $1(0.6)$ & \\
\hline \multicolumn{7}{|c|}{ Body weight (kg) } \\
\hline $30-60$ & $3(1.8)$ & 19 (11.6) & $42(25.7)$ & 39 (23.9) & $3(1.8)$ & \multirow{3}{*}{$0.018^{* *}$} \\
\hline $61-90$ & $0(0.0)$ & $7(4.2)$ & $25(15.3)$ & $18(11.0)$ & $4(2.4)$ & \\
\hline$\geq 91$ & $0(0.0)$ & $3(1.8)$ & $0(0.0)$ & $0(0.0)$ & $0(0.0)$ & \\
\hline \multicolumn{7}{|c|}{ NSCLC Stage } \\
\hline III A & $1(0.6)$ & $7(4.2)$ & $4(2.4)$ & $6(3.6)$ & $0(0.0)$ & \multirow[t]{3}{*}{0.367} \\
\hline III B & $1(0.6)$ & $4(2.4)$ & $21(12.8)$ & $13(7.9)$ & $0(0.0)$ & \\
\hline IV & $1(0.6)$ & $18(11.0)$ & $42(25.7)$ & $38(23.3)$ & $7(4.2)$ & \\
\hline
\end{tabular}

${ }^{a}$ Chi-square test, ${ }^{*} \mathrm{p}<0.01,{ }^{*} \mathrm{p}<0.05$, NSCLC: Non-small cell lung cancer, ECOG: Eastern Cooperative Oncology Group, PS: Performance status

Table 3: Impact of PS on survival in advanced NSCLC patients

\begin{tabular}{|c|c|c|c|c|c|}
\hline \multirow[t]{2}{*}{ Variable } & \multirow[t]{2}{*}{ n (\%) } & \multicolumn{2}{|l|}{ Univariate } & \multicolumn{2}{|l|}{ Multivariate } \\
\hline & & Median OS (days) & $\mathbf{p}^{\mathbf{b}}$ & HR $(95 \%$ CI) & $\mathbf{p}^{\mathrm{c}}$ \\
\hline \multicolumn{6}{|l|}{ ECOG PS } \\
\hline 0 & $3(1.8)$ & - & $0.003 *$ & $5.101(3.291-7.907)$ & $0.000^{* *}$ \\
\hline 1 & 29 (17.8) & - & & $0.297(0.057-1.542)$ & $0.000^{* *}$ \\
\hline 2 & 67 (41.1) & 377 & & $0.320(0.157-0.655)$ & 0.149 \\
\hline 3 & $57(35.0)$ & 397 & & $1.117(0.712-1.753)$ & $0.002^{*}$ \\
\hline $4^{\mathrm{a}}$ & $7(4.3)$ & 253 & & - & 0.631 \\
\hline
\end{tabular}

a Reference group in multivariate analysis, ${ }^{b}$ Kaplan-Meier method, ${ }^{c}$ Cox proportional hazard regression, ${ }^{*}$ p $<0.01,{ }^{* *}$ p $<0.001$, ECOG: Eastern Cooperative Oncology Group, PS: Performance status, OS: Overall survival, HR: Hazard ratio, CI: Confidence interval 
0 - Fully active, able to carry on all pre-disease performance without restriction

$\mathbf{1}$ - Restricted in physically strenuous activity but ambulatory and able to carry out work of light and sedentary nature (e.g., lighthouse work, office work)

2 - Ambulatory and capable of all self-care but unable to carry out any work activities. Up and about more than $50.0 \%$ of waking hours

3 - Capable of only limited self-care, confined to bed or chair more than $50.0 \%$ of waking hours

4 - Completely disabled. Cannot carry on any self-care. Totally confined to bed or chair

5 - Dead

Fig. 1: Eastern Cooperative Oncology Group, performance status scores description



Fig. 2: Kaplan-Meier survival curve for Eastern Cooperative Oncology Group, performance status scores

of ECOG PS with age. Patients on diagnosis having body weight $<61 \mathrm{~kg}$ were more frequently having EGOG PS score of $2(25.7 \%)$ followed by ECOG PS score of 3 (23.9\%). Dewys et al. [14] stated that poor body weight was associated with decreased PS.

The present study demonstrated that patients with ECOG PS score of 4 had worse survival which was similar to the study by Simmons et al. [8] who also observed least survival among patients having ECOG PS score of 4 . The findings of the Cox proportional hazard model suggested that hazard to death was decreased in patients with ECOG PS 0 and increased in patients with ECOG PS 2. Likewise, Radzikowska et al. [15] also found that survival was worse in ECOG PS 2 patients as compared to patients with ECOG PS score of 0 . Hence, both current and later study confirmed PS as a significant independent prognostic factor for survival in advanced NSCLC.

\section{CONCLUSION}

PS is a strong prognostic factor of survival in advanced NSCLC. In translating this to clinical care, PS should be examined in the setting of treatment stratification among advanced NSCLC patients.

\section{REFERENCES}

1. Parkin DM, Pisani P, Ferlay J. Estimates of the worldwide incidence of 25 major cancers in 1990. Int J Cancer 1999;80(6):827-41.

2. Azzoli CG, Temin S, Aliff T, Baker S, Brahmer J, Johnson DH, et al. 2011 focused update of 2009 American society of clinical oncology clinical practice guideline update on chemotherapy for stage IV nonsmall cell lung cancer. J Clin Oncol 2001;29(28):3825-31.

3. Boukovinas I, Kosmidis P. Treatment of non-small cell lung cancer patients with performance status 2 (PS2). Lung Cancer 2009;63(1):10-5.

4. Albain KS, Crowley JJ, LeBlanc M, Livingston RB. Survival determinants in extensive-stage non-small-cell lung cancer: The Southwest oncology group experience. J Clin Oncol 1991;9(9):1618-26.

5. Karnofsky DA, Burchenal JH. The clinical evaluation of chemotherapeutic agents in cancer. In: Macleod CM, editor. Evaluation of Chemotherapeutic Agents. New York: Columbia University Press; 1949. p. 199-205.

6. Oken MM, Creech RH, Tormey DC, Horton J, Davis TE, McFadden ET, et al. Toxicity and response criteria of the Eastern cooperative oncology group. Am J ClinOncol1982;5(6):649-55.

7. Blagden SP, Charman SC, Sharples LD, Magee LR, Gilligan D. Performance status score: Do patients and their oncologists agree? Br J Cancer2003;89(6):1022-7.

8. Simmons CP, Koinis F, Fallon MT, Fearon KC, Bowden J, Solheim TS, et al. Prognosis in advanced lung cancer-a prospective study examining key clinic-pathological factors. Lung Cancer 2015;88(3):304-9.

9. Liam CK, Pang YK, Leow CH, Poosparajah S, Menon A. Changes in the distribution of lung cancer cell types and patient demography in a developing multi-racial Asian country: Experience of a university teaching hospital. Lung Cancer 2006;53(1):23-30.

10. Hashim CW, Omar A, Abdullah S, Ismail AT. Prevalence and factors for non-resectable lung cancer at presentation. Aust Asian J Cancer 2010;9(1):61-6.

11. Youlden DR, Cramb SM, Baade PD. The international epidemiology of lung cancer: Geographical distribution and secular trends. J Thorac Oncol 2008;3(8):819-31.

12. Srisam-Ang K, Podhipak A, Narksawat K, Supaattagorn P, Tipayamongkholgul M. Survival of patients with advanced non-smallcell lung cancer at Ubon Ratchathani cancer center, Thailand. Southeast Asian J Trop Med Public Health 2005;36(4):994-1006.

13. Kawaguchi T, Takada M, Kubo A, Matsumura A, Fukai S, Tamura A, et al. Performance status and smoking status are independent favorable prognostic factors for survival in non-small cell lung cancer: A comprehensive analysis of 26,957 patients with NSCLC. J Thorac Oncol 2010;5(5):620-30.

14. Dewys WD, Begg C, Lavin PT, Band PR, Bennett JM, Bertino JR, et al. Prognostic effect of weight loss prior to chemotherapy in cancer patients. Eastern cooperative oncology group. Am J Med 1980;69(4):491-7.

15. Radzikowska E, Glaz P, Roszkowski K. Lung cancer in women: Age, smoking, histology, performance status, stage, initial treatment and survival. Population-based study of 20561 cases. Ann Oncol 2002;13(7):1087-93. 